\title{
Perceived barriers to leisure time physical activity: What Brazilians have to say?*
}

\author{
Emerson Sebastião ${ }^{1 \#}$, Wojtek Chodzko-Zajko ${ }^{1}$, Andiara Schwingel ${ }^{1}$, Lilian T. B. Gobbi ${ }^{2}$, \\ Camila B. Papini ${ }^{2}$, Priscila M. Nakamura ${ }^{2}$, Américo V. Netto ${ }^{2}$, Eduardo Kokubun ${ }^{2}$, \\ Sebastião Gobbi ${ }^{2}$
}

${ }^{1}$ Department of Kinesiology and Community Health, University of Illinois, Urbana-Champaign, USA;

${ }^{\#}$ Corresponding Author: esebast2@illinois.edu

${ }^{2}$ Department of Physical Education, Universidade Estadual Paulista-UNESP, Rio Claro, Brazil

Received 2 June 2013; revised 1 August 2013; accepted 22 October 2013

Copyright (C) 2013 Emerson Sebastião et al. This is an open access article distributed under the Creative Commons Attribution License, which permits unrestricted use, distribution, and reproduction in any medium, provided the original work is properly cited.

\begin{abstract}
Background: Physical inactivity is a major public health concern worldwide. Leisure time is an important domain of physical activity that draws the attention of researchers due to its voluntary characteristic. Understanding the barriers that prevent individuals being engaged in leisure time physical activity should be an ongoing concern that has the potential to lead to better strategies and interventions to promote physical activity in the populations. Objectives: This study explored perceived barriers to leisure time physical activity (LTPA) in Brazilian adults living in a midsize city. Methods: A total of 1213 adults were evaluated on barriers to LTPA. LTPA was assessed using the section four of the International Physical Activity Questionnaire. Barriers were assessed using a list of 22 factors that prevent individuals being engaged in LTPA. Results: Women, insufficiently active men and women, and low incoming individuals reported a higher number of barriers in average compared to their counterparts. Lack of time and feeling too lazy presented the strongest association with being inactive during leisure time. Conclusions: Understanding factors related to physical inactivity can help authorities in creating strategies, and developing effective health promotion programs.
\end{abstract}

Keywords: Barriers; Physical Activity; Leisure

\section{INTRODUCTION}

Physical inactivity is a major risk factor for morbidity

*Funding: This study was funded by Fundaçao de Amparo a Pesquisa do Estado de Sao Paulo, Brazil (process number: 2007/02229-4 FAPESP). and mortality [1]. Beyond its negative effects on health and quality of life, physical inactivity also contributes to increased health care costs [2,3]. Despite the clear benefits of physical activity for health outcomes [4,5] and the public health efforts to promote physical activity among the populations, studies have shown that physical inactivity rates remain high worldwide, especially in Latin America [6,7]. For instance, studies conducted in different regions of Brazil observed that $40 \%$ to $65 \%$ of the adults did not meet the recommended guidelines of 150 minutes/week of moderate physical activity $[8,9]$. In addition, results from a national surveillance conducted in all Brazilian capitals observed that the rates for inactivity during leisure time are even higher [10].

The non-engagement in regular physical activity has been associated with perceptions of barriers [11-13]. For instance, Reichert and colleagues observed that $85 \%$ of the adults assessed in their study reported at least one barrier to engaging in leisure time physical activity. Moreover, several barriers were positively associated with physical inactivity during leisure time [11]. Studies conducted to investigate perceived barriers for physical activity have verified that both personal (e.g. lack of motivation) and environmental barriers (e.g. safety environment) are frequently reported among population [1418] and have a negative effect on physical activity participation [19].

Leisure time is one of the four domains related to physical activity that represents a meaningful portion of the total amount of physical activity, especially regarding adults. Furthermore, studies employing self-reported physical activity measures have focused on understanding patterns and determinants of physical activity during leisure time and transportation due to problems in accurate acquiring physical activity information at work and in household-related tasks [20,21]. 
Despite the emphasis of studies on barriers related to physical activity, few have addressed this issue in representative samples in Latin America, especially in Brazil. It is known that physical activity may be influenced by several factors, among which personal, social and environmental factors play an important role in determining health attitudes, especially regarding to leisure time physical activity [22]. Therefore, additional studies are needed to identify barriers to leisure time physical activity among Brazilians if we are to be able to develop effective strategies for physical activity promotion, and to assist in the development of public health policies that promote active living. In addition, a better understanding of the factors that prevent people from engaging in leisure time physical activity may help health professionals and practitioners to work with sedentary individuals to overcome such barriers and achieve health benefits through physical activity. This is especially important in Latin America countries, including Brazil, which appears to have a higher prevalence of physical inactivity compared to developed nations and where obesity rates raise concern $[6,23,24]$. A developing country with a growing economy like Brazil may have different factors which prevent individuals from engaging in leisure time physical activity. This might be because of the large geographic territory, diverse regions with markedly different cultural and climate characteristics, each of which could influence individuals' perceptions of barriers.

Therefore, the present study explored perceived barriers to leisure time physical activity in Brazilian adults living in a midsize Brazilian city. For a better understanding, this study operationalized leisure time physical activity as being activities that are not work-oriented or that do not involve life maintenance tasks such as household chores. Thereby, leisure time is here understood as the time free of social obligations.

\section{METHODS}

A cross-sectional, population-based study was conducted in Rio Claro, Sao Paulo, Brazil, a midsize city $\left(190,000\right.$ inhabitants - density of $\left.124.36 / \mathrm{km}^{2}\right)$ located in southeastern Brazil to assess barriers to leisure time physical activity in a sample of adults over the age 20 years. The UNESP - Sao Paulo State University Ethical Committee approved the research protocol, and informed consent was obtained from each subject before data collection.

\subsection{The Study Site}

Rio Claro has a territorial area of nearly $490 \mathrm{~km}^{2}$ with an elevation of $613 \mathrm{~m}$. The city is located in the Mideast of Sao Paulo State approximately $190 \mathrm{~km}$ from the capital Sao Paulo. The population is predominantly White
(75\%) and Roman Catholic (nearly 59\%). The economic, historic and cultural development of the city has been influenced by the high concentration of Italian immigrants who came to the region about one hundred years ago. Rio Claro weather can be considered tropical with two well defined seasons: 1) tropical dry and; 2) humid. The mean annual temperature ranges from 18.1 to 20.9 degree Celsius with few periods of rain. It is different from the subtropical weather found in the capital Sao Paulo, the subtropical humid conditions observed in the South of the country, and equatorial/tropical humid features of the North (www.ibge.gov).

\subsection{Sample}

A stratified random sampling procedure was used to select a representative sample of adults living in Rio Claro. From the total number of census tracts $(n=200)$, 100 were randomly selected for inclusion in the study and eight households within each tract were randomly chosen for interview. This yielded a total of 800 households selected for interview. All residents in each household over 20 years of age who were able to walk independently were eligible for inclusion in the study. This procedure yielded a sample of 1572 individuals assessed. As the present study is part of a large survey with different purposes, the present analyzed only adults (20 to 59 years old). Therefore, the final sample was composed by 1213 individuals.

\subsection{Measures}

Barriers to leisure time physical activity were assessed using the Questionnaire of Barriers to Physical Activity Practice (QBPAP). The original version of the present instrument was developed by Hirayama in 2006 and used a likert scale to attend the purposes of his thesis [25]. In order to be employed and to attend the purpose of the present study, the QBPAP was modified to a list of 22 dichotomous (yes/no) factors and previous tested in a pilot study. Details of the questionnaire as well as a publication using the referred instrument can be found elsewhere [26].

Leisure time physical activity was assessed using the section four of the Portuguese long version of the International Physical Activity Questionnaire. The validation and reliability of the IPAQ are described elsewhere [27], including the validation for Brazilian population [28]. For the purpose of this study, insufficient physical activity was defined as situations in which the participant did not reach the recommended amount of 150 minutes per week [29]. Therefore, Individuals who reported less than 150 minutes of combined moderate and vigorous physical activity were considered to be insufficient active during leisure time. Similarly, individuals reporting at 
least 150 minutes of combined moderate and vigorous physical activity were considered to be sufficiently active to achieve health benefits. The IPAQ defines moderate activities as those that produce a moderate increase in respiration rate, heart rate, and sweating and last for at least 10 minutes. Vigorous activities are defined as those producing more substantial increases in the same variables.

In addition, the following demographic variables were collected, gender, age, education, and Socio Economic Status (SES). SES was defined according to the procedure of the Brazilian Economic Criteria Classification (www.abep.org), proposal by Brazilian Association of Research Companies and we grouped participants into three SES groups (High; Medium; and Low income group).

\subsection{Data Collection}

Questionnaires were both administered face-to-face by trained interviewers. The interviewers received 40 hours of training for administering and coding the questionnaires and were not aware of the objectives of the study. Moreover, the interviewers were oriented on the interpretation of terms such as moderate and vigorous physical activity and some commons examples of activities. In each of the selected households interviewers performed the assessments for all eligible participants, following inclusion criteria previous described. If participants were not at home in the first time visit, two more visits in different times were scheduled with at least one being during the weekend. In the case of two or more eligible participants were at home, the interviewers were instructed to perform each evaluation separately to avoid response interference.

Fieldwork supervisors were responsible to ensure quality of the data. The interviewer's questionnaires were checked in a period not exceeding one week following the initial interview (30\% checked by telephone and 10\% with the supervisor returning to the participant's house). This process identified inconsistencies in about three percent of interviews, which were repeated.

\subsection{Statistical Analysis}

The data were analyzed with standard statistical procedures using SPSS 13.0. Descriptive statistics included mean, standard deviation and percentage. Differences between groups were calculated using U Mann Whitney and Kruskall Wallis tests, adopting $\mathrm{p}<0.05$. Logistic regression was used to verify associated barriers to physical inactivity using $95 \%$ of confidence interval.

\section{RESULTS}

The final sample consisted of 1213 individuals. De- tails of the sample characteristics, separated by gender are presented in Table 1. According to the physical activity criteria adopted, within 1213 individual assessed 910 (approximately 75\%) were classified as insufficiently active $(<150 \mathrm{~min} /$ week $)$ during leisure time, being the prevalence greater in women $(76.9 \%)$ than men $(70.6 \%)$.

\section{Barriers to Leisure Time Physical Activity}

Nearly $97 \%$ of the participants reported at least one barrier (mean 5.72 barriers) to engage in leisure time physical activity. Statistical differences regarding the mean number of reported barriers were examined in different subsets. Women in general, men and women classified as insufficient active and low-income men and women reported higher number of barriers in average compared to their counterparts. No differences regarding mean number of reported barriers were found between age groups. Figure 1 displays in detail this information.

The main barriers reported were: need to rest, too lazy, enough active, lack of company, lack of money, lack of near places, and lack of time with rates over $40 \%$. Regarding sex, the barriers need to rest and too lazy was reported by over $50 \%$ of men and nearly $45 \%$ of women. Analyzed by age groups, the youngest group (20 - 39 years old) presented higher rates for the same barriers compared to the oldest age group (40 - 59 years old). Lack of time and lack of a nearby place to be active were among barriers identified by the low SES group, with rates of nearly $55 \%$. All reported barriers are displayed separately for sex (Figure 2), age group (Figure 3), and SES (Figure 4).

The association between leisure time physical activity and barriers was examined. Five barriers were found to be positively associated with physical inactivity during leisure time. After adjustments, the barrier "lack of time" presented the highest odds ratio (nearly 4 times) for lei-

Table 1. Demographic data.

\begin{tabular}{ccc}
\hline & Men (n = 523) & Women (n = 690) \\
\hline Age, years, mean (SD) & $38.4(12)$ & $39(11)$ \\
SES, n (\%) & & \\
High & $196(37.4)$ & $230(33.4)$ \\
Medium & $251(47.9)$ & $327(47.4)$ \\
Low & $77(14.7)$ & $133(19.2)$ \\
Schooling, n (\%) & & \\
$\geq 11$ yrs & & $270(39.2)$ \\
$<8$ yrs & $91(17.2)$ & $136(19.6)$ \\
\hline
\end{tabular}

\footnotetext{
\%\% within sex.
} 


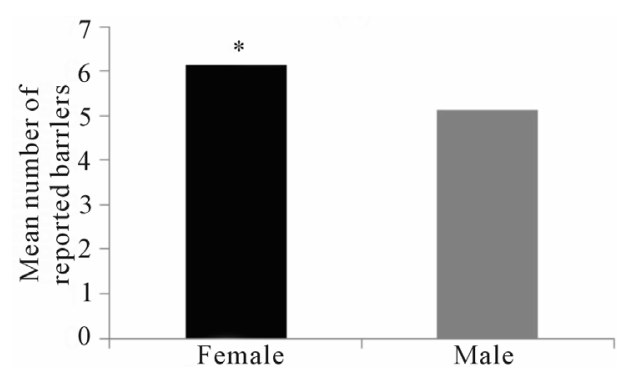

(a)

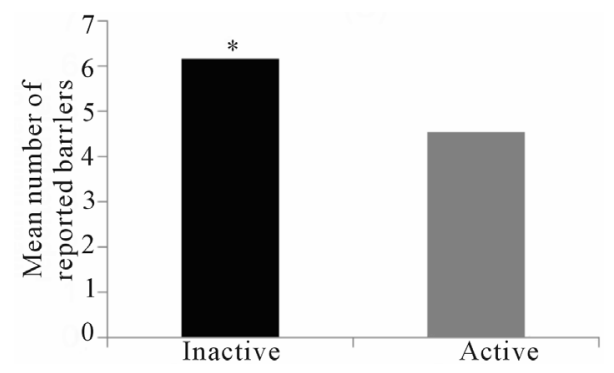

(c)

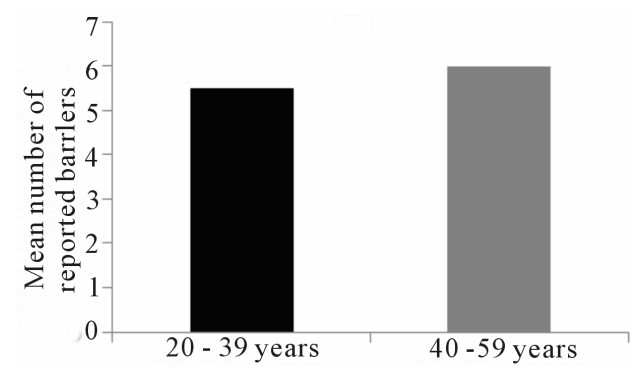

(b)

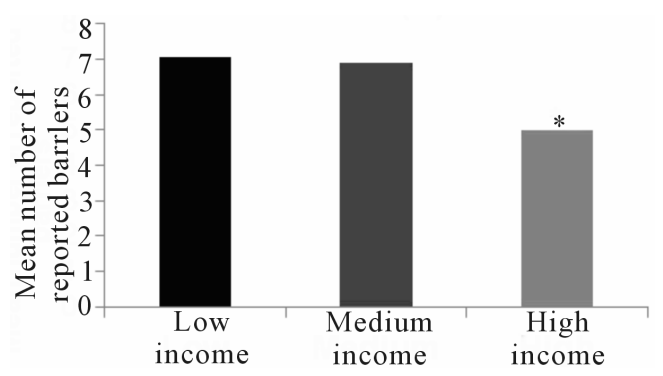

(d)

Figure 1. Mean number of reported barriers by sex (a), age group (b), physical activity level (c), and socioeconomic status $(d) .{ }^{*}$ Statistically significant $(p<0.05)$.

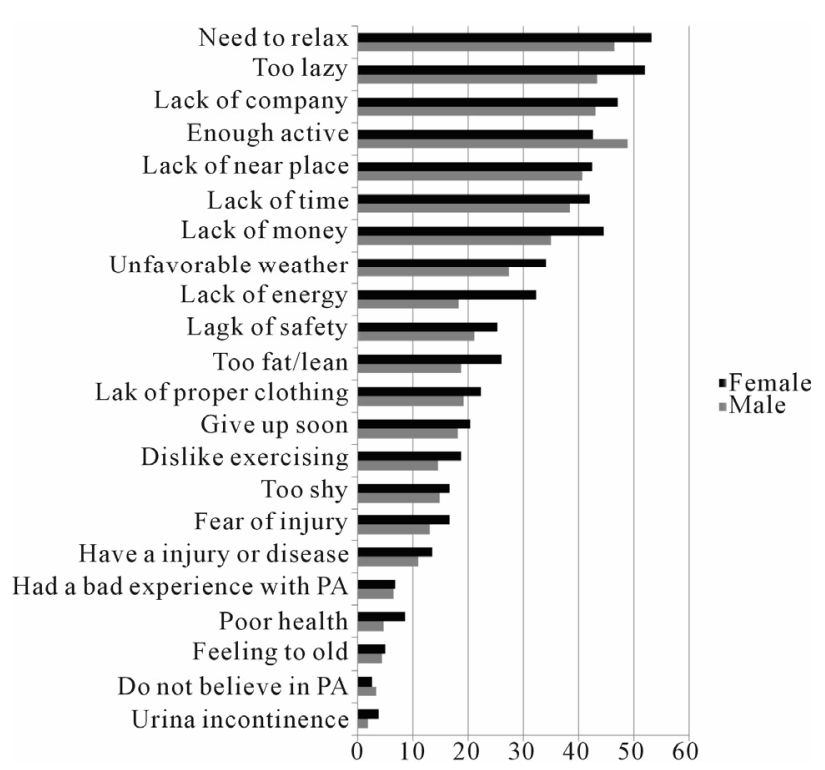

Figure 2. Prevalence of leisure time physical activity barriers separated by sex.

sure time physical inactivity compared to other barriers. Table 2 presents the results of the regression analyses in detail.

\section{DISCUSSION}

The present study aimed to explore perceived barriers to leisure time physical activity in adults living in a midsize Brazilian city. Additionally, it sought to provide insight regarding physical activity barriers in a developing country experiencing a rapid economic transition.
According to the criteria adopted in the present study, nearly $75 \%$ of the participants were considered insufficient active during leisure time. These findings are consistent with previous studies which have assessed leisure time physical inactivity not only in other Brazilian regions, but in other countries of Latin America and Asia [10,32]; however different rates have been observed in the United States and some European Countries [33,34]. Taken together these findings support the notion that physical inactivity remains a public health concern not only in Brazil but also in other Latin America countries. Although only leisure time physical activity was assessed in the present study, it is known that such domain significantly contributes to the total amount of physical activity, especially considering the age examined in the present study. Considering the negative effects of physical inactivity (for example: increased risk to develop chronic diseases and the associated health care costs), the findings observed in the present study should be a concern to authorities, professionals involved in health promotion, and policy makers. For instance, national data demonstrate that the capital Sao Paulo (where Rio Claro is located) is among the top four states regarding levels of overweight $(48 \%)$. Nevertheless the overweight rates observed in Sao Paulo are lower compared to some other Brazilian regions, such as, the North and South with rates over $50 \%$. In addition, obesity rates are a concern throughout the country [10]. The cost to authorities for the treatment of problems directly related to physical inactivity is high and studies have shown that a small increase in physical activity at the population level can 


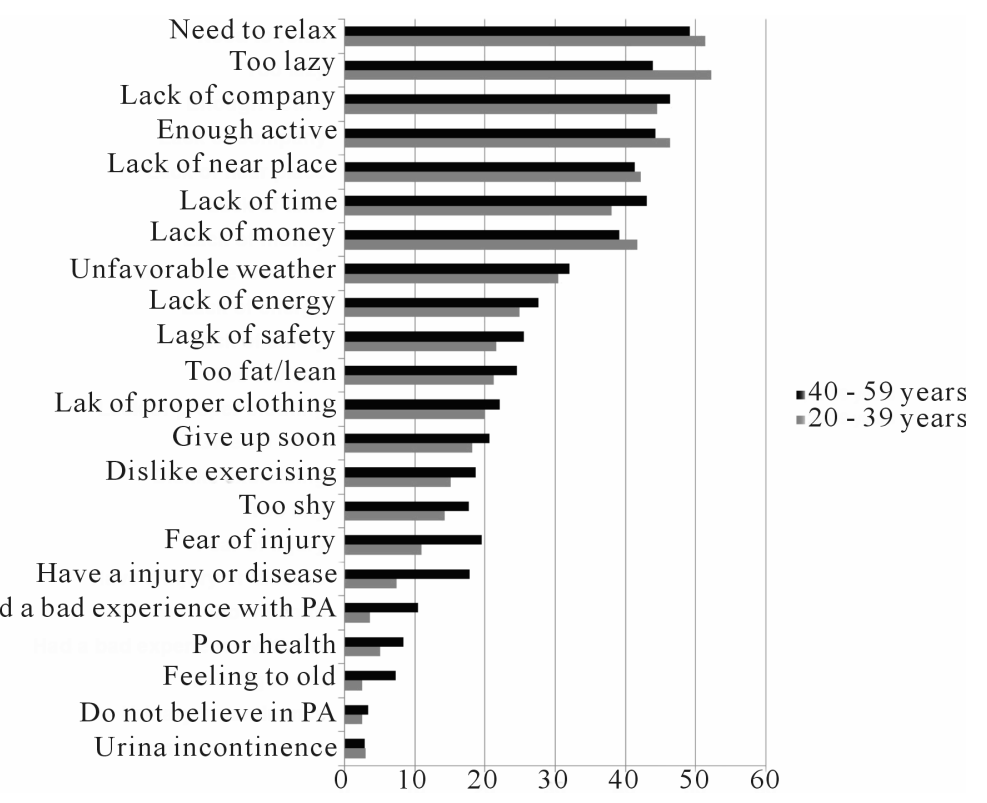

Figure 3. Prevalence of leisure time physical activity barriers separated by age group.

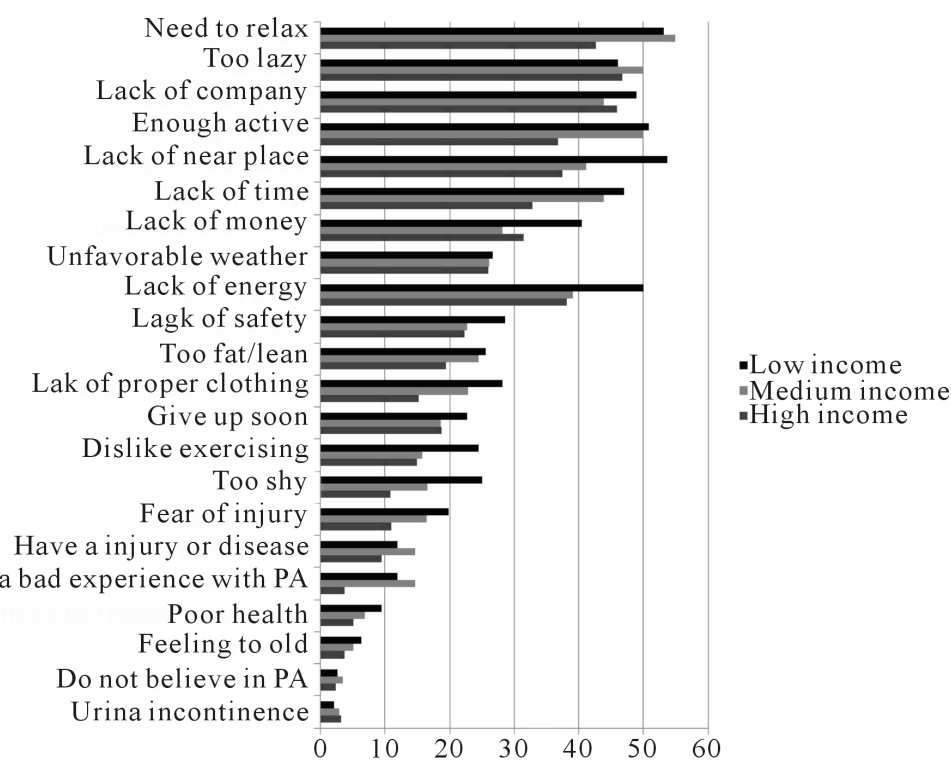

Figure 4. Prevalence of leisure time physical activity barriers separated by socioeconomic groups.

Table 2. Multiple logistic regression models for barriers to physical activity and leisure time physical inactivity.

\begin{tabular}{ccrr}
\hline Barriers & Crude Analysis OR (CI-95\%) & Adjusted Analysis ${ }^{* \dagger}$ OR $(\mathrm{CI}-95 \%)$ & $\mathrm{p}$ \\
\hline Lack of time & $4.32(2.821-6.635)$ & $3.86(2.357-6.320)$ & 0.001 \\
Too lazy & $3.36(2.342-4.846)$ & $2.55(1.641-3.976)$ & 0.001 \\
Need to rest & $2.80(1.892-4.148)$ & $1.98(1.242-3.158)$ & 0.004 \\
Lack of energy & $3.86(2.306-6.459)$ & $2.14(1.148-4.012)$ & 0.02 \\
Dislike exercising & $3.90(2.031-7.488)$ & $2.84(1.340-6.032)$ & 0.03 \\
\hline
\end{tabular}

*Adjusted analysis by sex, age, schooling, socio economic status and all other barriers which presented significant level of $<0.2$; ${ }^{\dagger}$ Hosmer-Lemeshow test for residual analysis $(0.69)$. 
be successful in reducing such costs $[2,3,35]$. Thereby, strategies to promote physical activity, like communitybased interventions, and community-wide polices and planning appear to be the best alternative so far to increase physical activity level of the population $[36,37]$.

Regarding barriers, the large number of barriers reported by the participants in this study is consistent with the high rates of physical inactivity observed in this sample. The present study observed that $97 \%$ of the participants reported at least one barrier to physical activity during leisure time, and the mean average number of reported barriers was 5.72. Similar rates in the average number of barriers have also been observed elsewhere [11]. It is noteworthy that studies involving barriers to physical activity are extremely difficult to compare because relatively few standardized instruments exist for the evaluation of physical activity barriers. To our knowledge, to date, no valid instrument that combines personal and environmental barriers has been developed.

In the present study, we found that women, insufficient active men and women, and low-income men and women reported more barriers. These findings are in parallel with the high physical inactivity levels observed in these groups. These findings suggest that communitybased interventions and public health strategies should concentrate efforts on these subgroups in order to reach and help them overcoming such barriers and increase their physical activity level. The most frequently reported barriers were: lack of time, enough active, lack of company, lack of money, lack of near place for practice, need to rest, and too lazy $(\geq 40 \%)$. However, only the barriers lack of time, too lazy, lack of energy, need to rest, and disliking exercise were positive associated with leisure time physical inactivity. These findings are similar of those published elsewhere $[11,38,39]$. Despite the association and high prevalence found in these barriers, studies have suggested that barriers such as lack of energy, lack of company, and lack of time suggest a lack of motivation for physical activity; and motivation factors have been shown to be associated with physical activity levels $[13,40,41]$. According to Cerin and colleagues motivation can be related to not only the "pure" motivation (a person that has or has not the enjoyment of physical activity), but also to environmental, social and health-related factors that could be related to motivation as a barrier [39]. In this sense, social support may pose as a positive factor for affect motivation to physical activity/exercise.

Additionally, non-participation in physical activity during leisure time has been independently associated with lack of time, which is one of the most frequent barriers reported in the adult population in general $[11,12,42$, 43]. Lack of time was positively associated with physical inactivity in the present study. Bowles and colleagues, found a strong link between lack of time as a barrier and lack of self-motivation for physical activity [39]. According to Reichert and colleagues most part of the adult population in Brazil have free time only at night and they may not consider the night a good time for physical activity due to safety concerns [11]. Regarding safety, the present study found that lack of safety was reported by nearly $20 \%$ of men and approximately $30 \%$ of women. Although it was not associated with leisure-time physical activity in the present study, such association has been observed by Bennett and colleagues and therefore, worth of attention [44]. These authors concluded that residing in a neighborhood that is perceived to be unsafe at night is a barrier to regular physical activity. Additionally, feeling unsafe may also diminish confidence in the ability to be more physically active. Taken together, these findings leave room for public health strategies and health professionals regarding physical activity and public safety. Physical activity promotion should focus in all possible types/domains of physical activity. As Brazilians appear to have difficult to find time to be physically active during leisure time, they should be encouraged to explore other types of physical activity, for example commuting from home to work. Additionally, as they might not feel safe exercising during the night, measures regarding enhance the lighting of possible places for physical activity, such as parks, and increase policing near this places, should be taken and might be an important step to promote and increase not only leisure time physical activity in general of the Brazilian adult population.

Lack of money was among the most frequently reported barriers to leisure time physical activity, especially among the low SES population. Our data suggest that participants in our study do not appear to recognize that some forms of physical activity (e.g. walking) require little financial expenditures and can still bring substantial health benefits $[45,46]$. A study conducted in Brazil suggests that many of the Brazilian population associate the health benefits of physical activity primarily with participating in organized sports and/or attending fitness centers [11]. The relative lack of public fitness centers and sports facilities may lead to the perception that there are no nearby places to be physically active reported in our study (prevalence $\geq 40 \%$ ). Such a barrier has been shown to be associated with physical inactivity in a different study [47]. Individuals in our study may not feel safety walking in their neighborhood thus it is important to increase our understanding of the possible effects of the environment on physical activity levels and to explore the degree to which the built environment can be changed to facilitate physical activity [35].

The present study sought to address the main perceived barriers to engage in leisure time physical activity 
in adults living in a midsize Brazilian city. Our findings suggest that multilevel interventions are needed to help to overcome perceived barriers to leisure time physical activity in the adult Brazilian population. It is noteworthy that some of the barriers reported by the participants may not be modifiable, however the availability of social support and access to safe locations for example, may be. It is important to note that the present study has some strengths and limitations. The methodology employed to select the sample, collect data, and the valid instruments employed are the strengths of this study. Important findings were observed which are of interest to the field of public health and physical activity promotion. Although important, our findings should be interpreted with caution due to the following limitations. We use a subsection (leisure time) of the IPAQ questionnaire. Albeit widely used, studies have reported that IPAQ questionnaire has problems to accurately estimate physical activity level $[20,21]$. Additionally, we use the DHHS criteria (150 minutes/week) to classify the participants either as insufficient active or active [29]. The DHHS criteria is related to the four physical activity domains, therefore, individuals who do not meet the 150 minutes threshold in the present study (presenting less than 150 minutes/week of physical activity in leisure time), may have been categorized as active if other domains (transportation, work, and household-related physical activity) were considered. Second, as the participants were specifically instructed to report only the barriers related to leisure time physical activity, we do not know if these barriers would be reported for other types of physical activity, for example, transportation. It is important because in a public health perspective physical activity is related to all four domains and not only leisure time. Moreover, the present study used a 22-item list factors instrument to assess barriers. Although it was a large instrument compared to other studies, the QBPAP does not provide any open ended questions. It means that it is possible that the participants could have additional barriers than the ones listed in the referred questionnaire.

Additional studies aimed at exploring possible factors (barriers) that prevent or make it difficult to individuals from engaging in regular physical activity are needed. The findings of the present study demonstrate that physical inactivity during leisure time is prevalent in Brazilian adults and a multilevel intervention to increase activity is needed. Physical activity is a complex and dynamic process. Developing strategies to increase physical activity poses a challenge for individuals, health professionals, public policy makers, and authorities. Understanding the determinants of physical inactivity can help authorities to create strategies, develop health promotion programs, effective community-based interventions, as well as public policies that have the potential of making the difference.

\section{ACKNOWLEDGEMENTS}

The authors thank the Coordenação de Aperfeiçoamento de Pessoal de Nível Superior-CAPES; Fundação Municipal da Saúde de Rio Claro, Brazil and the Conselho Regional de Educação Física do Estado de Sao Paulo, Brazil (CREF04/SP).

\section{REFERENCES}

[1] WHO (2009) Global Health Risks. Mortality and burden of disease attributable to selected major risks. Report, World Health Organization.

http://www.who.int/healthinfo/global_burden_disease/Gl obalHealthRisks_report_full.pdf

[2] Katzmarzyk, P.T. and Janssen, I. (2004) The economic costs associated with physical inactivity and obesity in Canada: An update. Canadian Journal of Applied Physiology, 29, 90-115.

http://dx.doi.org/10.1139/h04-008

[3] Garrett, N.A., Brasure, M., Schmitz, K.H., Schultz, M.M. and Huber, M.R. (2004) Physical inactivity: Direct cost to a health plan. American Journal of Preventive Medicine, 27, 304-309. http://dx.doi.org/10.1016/S0749-3797(04)00191-6

[4] Chodzko-Zajko, W.J., Proctor, D.N., Singh, F., Minson, C. T., Nigg, C. R., Salem, G. J., et al. (2009) American College of Sports Medicine position stand. Exercise and physical activity for older adults. Medicine \& Science in Sports \& Exercise, 41, 1510-1530. http://dx.doi.org/10.1249/MSS.0b013e3181a0c95c

[5] Oja, P., Bull, F.C., Fogelholm, M. and Martin, B.W. (2010) Physical activity recommendations for health: What should Europe do? BMC Public Health, 10, 10. http://dx.doi.org/10.1186/1471-2458-10-10

[6] Dumith S.C., Hallal P.C., Reis, R.S. and Kohl, H.W. (2011) Worldwide prevalence of physical inactivity and its association with human development index in 76 countries. Preventive Medicine, 53, 24-28. http://dx.doi.org/10.1016/j.ypmed.2011.02.017

[7] Dumith, S.C. (2009) Physical activity in Brazil: A systematic review. Cadernos de Saúde Pública, 25, S415S426. http://dx.doi.org/10.1590/S0102-311X2009001500007

[8] Hallal, P.C., Victora, C.G., Wells, J.C. and Lima, R.C. (2003) Physical inactivity: Prevalence and associated variables in Brazilian adults. Medicine \& Science in Sports \& Exercise, 35, 1894-900.

http://dx.doi.org/10.1249/01.MSS.0000093615.33774.0E

[9] Siqueira, F.V., Facchini L.A., Piccini, R.X., Tomasi, E., Thumé, E., Silveira, D.S., et al. (2008) Physical activity in young adults and the elderly in areas covered by primary health care units in municipalities in the South and Northeast of Brazil. Cadernos de Saúde Pública, 24, 3954.

http://dx.doi.org/10.1590/S0102-311X2008000100005

[10] VIGITEL Brazil (2010) Telephone Surveillance of Risk and Protective Factors for Chronic Diseases Report. Ministry of Health, Brasilia.

http://bvsms.saude.gov.br/bvs/publicacoes/vigitel_2010.p 
$\underline{\mathrm{df}}$

[11] Reichert, F.F., Barros, A.J., Domingues, M.R. and Hallal, P.C. (2007) The role of perceived personal barriers to engagement in leisure-time physical activity. American Journal of Public Health, 97, 515-519. http://dx.doi.org/10.2105/AJPH.2005.070144

[12] Booth, M.L., Bauman, A., Owen, N. and Gore, C.J. (1997) Physical activity preferences, preferred sources of assistance, and perceived barriers to increased activity among physically inactive Australians. Preventive Medicine, 26, 131-137. http://dx.doi.org/10.1006/pmed.1996.9982

[13] Sherwood, N.E. and Jeffery, R.W. (2000) The behavioral determinants of exercise: implications for physical activity interventions. Annual Review of Nutrition, 20, 21-44. http://dx.doi.org/10.1146/annurev.nutr.20.1.21

[14] Heesch, K.C., Brown, D.R. and Blanton, C.J. (2000) Perceived barriers to exercise and stage of exercise adoption in older women of different racial/ethnic groups. Women Health, 30, 61-76. http://dx.doi.org/10.1300/J013v30n04 05

[15] King, A.C., Castro, C., Wilcox, S., Eyler, A.A., Sallis, J.F. and Brownson, R.C. (2000) Personal and environmental factors associated with physical inactivity among different racial-ethnic groups of U.S. middle-aged and olderaged women. Health Psychology, 19, 354-364. http://dx.doi.org/10.1037/0278-6133.19.4.354

[16] Zhu, W., Timm, G. and Ainsworth, B. (2001) Rasch calibration and optimal categorization of an instrument measuring women's exercise perseverance and barriers. Research Quarterly for Exercise \& Sport, 72, 104-116. http://dx.doi.org/10.1080/02701367.2001.10608940

[17] Wilcox, S., Castro, C., King, A.C., Housemann, R. and Brownson, R.C. (2000) Determinants of leisure time physical activity in rural compared with urban older and ethnically diverse women in the United States. Journal of Epidemiology \& Community Health, 54, 667-672. http://dx.doi.org/10.1136/jech.54.9.667

[18] Dawson, J., Hillsdon, M., Boller, I. and Foster, C. (2007) Perceived barriers to walking in the neighborhood environment: a survey of middle-aged and older adults. Journal of Aging and Physical Activity, 15, 318-335.

[19] Tucker, P. and Gilliland, J. (2007) The effect of season and weather on physical activity: A systematic review. Public Health, 121, 909-922. http://dx.doi.org/10.1016/j.puhe.2007.04.009

[20] Hallal, P.C., Gomez, L.F., Parra, D.C., Lobelo, F., Mosquera, J., Florindo, A.A., et al. (2010) Lessons learned after 10 years of IPAQ use in Brazil and Colombia. Journal of Physical Activity \& Health, 7, S259-264.

[21] Sebastião, E., Gobbi, S., Chodzko-Zajko, W., Schwingel, A., Papini, C.B., Nakamura, P.M., et al. (2012) The International Physical Activity Questionnaire-long form overestimates self-reported physical activity of Brazilian adults. Public Health, 126, 967-975.

http://dx.doi.org/10.1016/j.puhe.2012.07.004

[22] Dishman, R.K. (1994) Advances in exercise adherence. Human Kinetics, Champaign.

[23] Withrow, D. and Alter, D.A. (2011) The economic burden of obesity worldwide: A systematic review of the direct costs of obesity. Obesity Reviews, 12, 131-141. http://dx.doi.org/10.1111/j.1467-789X.2009.00712.x

[24] Sichieri, R., Nascimento, S. and Coutinho, W. (2007) The burden of hospitalization due to overweight and obesity in Brazil. Cadernos de Saúde Pública, 23, 1721-1727. http://dx.doi.org/10.1590/S0102-311X2007000700025

[25] Hirayama, M.S. (2006) Physical activity and Parkinson's disease: Behavior change, self-efficacy and perceived barriers. Thesis, Graduate program in human movement sciences of the Sao Paulo State University, Rio Claro. http://www.athena.biblioteca.unesp.br/exlibris/bd/brc/330 04137062P0/2006/hirayama_ms_me_rcla.pdf

[26] Gobbi, S., Sebastiao, E., Papini, C.B., Nakamura, P.M., Vadanha-Netto, A., Gobbi, L.T.B., et al. (2012) Physical inactivity and related barriers: A study in a community dwelling of older brazilians. Journal of Aging Research, 2012, 685190. http://dx.doi.org/10.1155/2012/685190

[27] Craig, C.L., Marshall, A.L., Sjöström, M., Bauman, A.E., Booth, M.L., Ainsworth, B.E., et al. (2003) International physical activity questionnaire: 12-country reliability and validity. Medicine \& Science in Sports \& Exercise, 35, 1381-1395.

http://dx.doi.org/10.1249/01.MSS.0000078924.61453.FB

[28] Pardini, R., Matsudo, S.M., Araújo, T., Matsudo, V., Andrade, E., Braggion, G., et al. (2001) Validation of the International Physical Activity Questionaire (IPAQ version 6): pilot study in Brazilian young adults. Revista Brasileira de Ciência e Movimento, 9, 7.

[29] DHHS (2008) Physical Activity Guidelines Advisory Committee Report.

http://www.health.gov/paguidelines/report/pdf/committee report.pdf

[30] Florindo, A.A., Guimaraes, V.V., Cesar, C.L., Barros, M.B., Alves, M.C. and Goldbaum, M. (2009) Epidemiology of leisure, transportation, occupational, and household physical activity: Prevalence and associated factors. Journal of Physical Activity \& Health, 6, 625-32.

[31] Gomez, L.F., Mateus, J.C. and Cabrera, G. (2004) Leisure-time physical activity among women in a neighbourhood in Bogota, Colombia: prevalence and socio-demographic correlates. Cadernos de Saúde Pública, 20, $1103-$ 1109. http://dx.doi.org/10.1590/S0102-311X2004000400026

[32] Shibata, A., Oka, K., Nakamura, Y. and Muraoka, I. (2009) Prevalence and demographic correlates of meeting the physical activity recommendation among Japanese adults. Journal of Physical Activity \& Health, 6, 24-32.

[33] Marshall, S.J., Jones, D.A., Ainsworth, B.E., Reis, J.P., Levy, S.S. and Macera, C.A. (2007) Race/ethnicity, social class, and leisure-time physical inactivity. Medicine \& Science in Sports \& Exercise, 39, 44-51. http://dx.doi.org/10.1249/01.mss.0000239401.16381.37

[34] Martínez-González, M.A., Varo, J.J., Santos, J.L., De Irala, J., Gibney, M., Kearney, J., et al. (2001) Prevalence of physical activity during leisure time in the European Union. Medicine \& Science in Sports \& Exercise, 33, 1142-1146.

http://dx.doi.org/10.1097/00005768-200107000-00011 
[35] Roux, L., Pratt, M., Tengs, T.O., Yore, M.M., Yanagawa, T.L., Van Den Bos, J., et al. (2008) Cost effectiveness of community-based physical activity interventions. American Journal of Preventive Medicine, 35, 578-588. http://dx.doi.org/10.1016/j.amepre.2008.06.040

[36] Heath, G.W., Parra, D.C., Sarmiento, O.L., Lars Bo, A., Owen, N., Goenka, S., et al. (2012) Evidence-based intervention in physical activity: Lessons from around the world. Lancet, 380, 272-281. http://dx.doi.org/10.1016/S0140-6736(12)60816-2

[37] Reis, R.S., Hallal, P.C., Parra, D.C., Ribeiro, I.C., Brownson, R.C., Pratt, M., et al. (2010) Promoting physical activity through community-wide policies and planning: Findings from Curitiba, Brazil. Journal of Physical Activity \& Health, 7, S137-S145.

[38] Sallis, J.F., Johnson, M.F., Calfas, K.J., Caparosa, S. and Nichols, J.F. (1997) Assessing perceived physical environmental variables that may influence physical activity. Research Quarterly for Exercise \& Sport, 68, 345-351. http://dx.doi.org/10.1080/02701367.1997.10608015

[39] Brownson, R.C., Baker, E.A., Housemann, R.A., Brennan, L.K. and Bacak, S.J. (2001) Environmental and policy determinants of physical activity in the United States. American Journal of Public Health, 91, 1995-2003. http://dx.doi.org/10.2105/AJPH.91.12.1995

[40] Cerin, E., Leslie, E., Sugiyama, T. and Owen, N. (2010) Perceived barriers to leisure-time physical activity in adults: an ecological perspective. Journal of Physical Activity \& Health, 7, 451-459.

[41] Bowles, H.R., Morrow, JR, Leonard, B.L., Hawkins, M. and Couzelis, P.M. (2002) The association between physical activity behavior and commonly reported barri- ers in a worksite population. Research Quarterly for Exercise \& Sport, 73, 464-470.

http://dx.doi.org/10.1080/02701367.2002.10609047

[42] Burton, N.W., Turrell, G. and Oldenburg, B. (2003) Participation in recreational physical activity: Why do socioeconomic groups differ? Health Education \& Behavior, 30, 225-244. http://dx.doi.org/10.1177/1090198102251036

[43] Sit, C.H.P., Kerr, J.H. and Wong, I.T.F. (2008) Motives for and barriers to physical activity participation in middle-aged Chinese women. Psychology of Sport and Exercise, 9, 18. http://dx.doi.org/10.1016/j.psychsport.2007.04.006

[44] Bennett, G.G., McNeill, L.H., Wolin, K.Y., Duncan, D.T., Puleo, E. and Emmons, K.M. (2007) Safe to walk? Neighborhood safety and physical activity among public housing residents. PLOS Medicine, 4, 1599-1606.

[45] Gilson, N., McKenna, J., Cooke, C. and Brown, W. (2007) Walking towards health in a university community: A feasibility study. Preventive Medicine, 44, 167-169. http://dx.doi.org/10.1016/j.ypmed.2006.09.012

[46] Wendel-Vos, W., Droomers, M., Kremers, S., Brug, J. and van Lenthe, F. (2007) Potential environmental determinants of physical activity in adults: A systematic review. Obesity Reviews, 8, 425-440. http://dx.doi.org/10.1111/j.1467-789X.2007.00370.x

[47] Peterson, R.D, Krivo, L.J. and Harris, M.A. (2000) Disadvantage and neighborhood violent crime: Do local institutions matter? Journal of Research in Crime and Delinquency, 37, 33. http://dx.doi.org/10.1177/0022427800037001002 